\title{
BENEFITS AND BARRIERS TO INTERNATIONAL COLLABORATION FOR CAPSTONE DESIGN COURSE
}

\author{
Narges Balouchestani Ali ${ }^{1}$, Sijia Zhu ${ }^{2}$ and Kamran Behdinan ${ }^{1}$ \\ ${ }^{1}$ Institute for Multidisciplinary Design \& Innovation (IMDI), University of Toronto \\ ${ }^{2}$ Ontario Institute for Studies in Education (OISE), University of Toronto \\ narges.balouchestaniasli@mail.utoronto.ca, cyn.zhu@mail.utoronto.ca, behdinan@mie.utoronto.ca
}

\begin{abstract}
In today's world, engineering design is being conducted in a global environment. Recent research in engineering education shows that one of the competencies for engineering students is the ability to collaborate and communicate internationally. There is no better place in curricula than the 4th year design capstone to incorporate international experiences for students. University of Toronto has recently started international collaboration in capstone by partnering with universities in China, USA and Singapore. This is problem-based learning that allows students to experience collaboration with international partners. This paper explores the experiences of students in the international capstone design courses. We investigate the challenges, the risks, and the rewards associated with this international and cross cultural collaboration.
\end{abstract}

Keywords: International Capstone Design Course, International Collaboration, Cross-cultural Communication

\section{INTRODUCTION}

\subsection{Motivation for an International Capstone}

In Canada, capstone design courses have become an integral part of engineering education over the past decade. Like most other institutions, capstone courses at the University of Toronto occur in single discipline or multidisciplinary teams. However, recently universities around the world have been adding international design teams or global virtual design teams as options for students participating in capstone design. Moving towards these transnational projects is not only motivating for upper year students but also functions to fill a gap in their education.

At the point in which students enter into upper year capstone design courses, they often have only a couple semesters left in their undergraduate education. These students have experienced collaborative teamwork in many occasions within the context of other courses. Many of them have also taken work terms and participated in collaborative groups in industry settings. In order to motivate these upper year students to actively participate in capstone design, the course itself must offer them opportunities for learning new knowledge that they have not previously encountered or allow them to apply their previous knowledge in a new context.

\subsection{Engineering with a Global Vision}

Engineers are vital in many science, technology, engineering and mathematics (STEM) integrated projects. As we enter into the $21^{\text {st }}$ century, engineering students not only need to have a strong grasp of engineering science fundamentals, a good understanding of design, and effective communication skill, they also must be "culturally sophisticated and prepared to work in an international work environment" as argued by Suarez-Orozco [1]. This cultural sophistication can be gained through navigating the relationships required by an international capstone that has sub-teams located in multiple countries with members from many different cultural backgrounds. This cross cultural collaboration enables engineering students to develop a global vision.

In addition to gaining the skills to work in an international workforce, participating in international capstone projects also gives students the opportunity to expand their design identity to encompass multinational and multi-cultural perspectives and values.

\subsection{Communication}

According to Brown and Seider [2], it has become increasingly important for organization to develop temporary design teams that operate for the duration of a project. These teams require individuals from all over the world with different types of academic, professional and cultural backgrounds to come together and collaborate productively within a tight timeline. This means that the members of these design collaborations need to adapt and develop effective relationships with team member through using various communication technologies.

Furthermore, with the increase in globalization, many industries are now transnational and looking for attributes such as good communication skills and international experience when hiring engineering graduates. According to Zaugg and Davies [3], 'soft' skills such as communication with team members is an 
essential part of international capstone design teams. While these 'soft' skills are also essential for local teams, the "different cultural background and the limitation of internet interaction" increases the need for effective virtual communication.

Haythornthwaite [4] states that there are three types of communication which are essential to building elearning partnerships: content related communications, planning of tasks, and social support. Content related communication and the planning of tasks mainly focus on specific learning goals while the social support type of communication is essential in relationship building [4]. Only when there is dedicated time towards both relationship building and learning goals will effective collaborations occur.

When communicating virtually, team members need to select technologies that are efficient and effective but also help build community. Hrastinski [5] suggests that there needs to be a balance between synchronous and asynchronous communication tools as each type has both advantages and disadvantages. According to Shachag and Hara [6] media-rich communications such as video conferencing enables greater team interactions and lead to the building of stronger and more trusting relationships. Asynchronous technologies function to mitigate language barriers as they allow team members the time to better understand each other [3].

\subsection{Developing Trust}

In order for international collaborations to be successful, team member must be able to quickly develop trust for one another. Zaugg and Davies [3] suggest that in order for a virtual team to develop strong and trusting relationships, team members need to invest time into learning about each other's non-project activities and interests. Furthermore, Zaugg and Davies [3] state that it is important for team members to be attentive to the language they use during communications. By reducing the amount of colloquial phrases and idioms when communicating with international team members, project groups will be able to reduce the amount of misunderstandings that can be detrimental to developing trust. Trusting relationships that have been established must be maintained through consistent and continuous communications. Furthermore, team members must actively and frequently acknowledge the contributions of individuals and sub teams.

\section{INTERNATIONAL CAPSTONE INFRASTRUCTURE}

As Downey defines: "In international experience students go beyond interacting with classroom peers to have collaborative work experiences with people who have been raised, educated, and living in the host country. A distinguishing feature is shared responsibility to bring a project to a successful conclusion" [7].

At the University of Toronto, international capstone is offered to students in the Department of Mechanical and Industrial Engineering and it is part of the mechanical engineering capstone. This international collaboration with China was initiated in 2011 by Professor Behdinan. Aside from China, the University of Toronto has collaborative programs with Singapore and the USA. In this study we focus on students' collaboration with Chinese University.

In an international capstone, students must produce the same deliverables as in the regular capstone, namely project requirements, design review, final design specification and showcase. Each international capstone team has a supervisor and a client similar to a regular capstone team. This year University of Toronto (UT) students collaborated with two universities in China and five universities in the United States. For the purpose of this paper we will focus on the collaboration with the Tsinghua University (TU) in China.

The capstone client, Partners for the Advancement of Collaborative Engineering education (PACE), has requested a Reconfigurable Shared-Use Mobility System (RSMS), as a means of transportation within an urban community. The design can potentially decrease traffic congestion and reduce negative environmental impacts in highly urbanized areas. The UT design team was tasked with the mechanical design of the project. They collaborated with TU team that was tasked to produce industrial designs that meet the functional design requirements while addressing the aesthetic demands of the North American market.

As a part of this international collaboration, the UT team traveled to China during the first semester to propose their design. TU students also traveled to Canada at the end of the second semester to show their industrial design at the UT capstone showcase.

\section{RESEARCH DESIGN}

This case-study follows one international capstone team of five UT students through their year-long collaboration with their TU teammates. Using a qualitative research design, data was collected through video-recordings of group meetings, semi-formal interviews, and field notes [8]. The methods were implemented sequentially so that the observations from the video-recordings informed the questions for the semi-formal interviews. In total, five hours of video were collected and five interviews with an average duration of $45 \mathrm{~min}$ were conducted.

Glauser and Strauss's grounded theory was used for data analysis [9]. Initial observations made from videorecordings were general in nature. Themes from the 
videos were then used to inform later interviews. The semi-formal interviews and field notes were then coded without pre-existing predictions, but instead we allowed the themes and categories to emerge from the codes.

The result of this research is limited by the number of participants and might be biased based on the nature of the project that was selected. A blurb was sent out to all international capstone students to participate in this research study and get compensated. This team volunteered for the video recording and interview and there was no pre-selection process. Also there was an application process for students to get in to international capstone, so the result is also biased by the selection criteria for getting into the international capstone.

\section{RESULTS AND DISCUSSION}

Student were asked a series of questions about their international capstone experience. The factors that motivated them to take this international experience along with their cross cultural experience emerged from these questions.

We performed open-coding to find thematic areas. Three main thematic areas were found. First, our results show that students originally choose international capstone because they realized the value of this learning experience from their previous working experience. Second, our results revealed that communication was the most challenging aspect of this international experience. Time differences and cultural barriers were the two sub-factors that made their communication challenging. Third, the difference in their educational background (students from China were specialized in industrial design and students from Canada were specialized in mechanical design) made their team multidisciplinary which had advantages and disadvantages. Benefits and barriers of international experience for each of these thematic areas are analyzed in the following sections.

As a qualitative study, the analysis is a result of the researcher's interpretation of the data.

\subsection{Authentic simulation of work environment}

Many engineering companies collaborate internationally. Often, manufacturing and automotive companies have their facilities and plants located abroad which requires their engineers to be able to collaborate internationally with other engineers. Engineering consulting firms also work with companies overseas. Having international collaboration experience can help recent engineering graduates to be qualified and surpass these company's expectation to secure a position in industry.

This international capstone project extends an existing component of engineering curricula for the students who want to be at the top of their graduating cohort. This was echoed by students coming back from their professional experience year (PEY). It was revealed during the interviews that students who did their professional experience year chose the international capstone project because they saw its value during their internship. The work experience that they had made them realize that having international experience and the skills associated with it would make them ideal candidates for many industries. As one participant mentioned:

"During my PEY in Magna we used to do many cross country collaboration, because a lot of manufacturing plants would be internationally located (US, India, china). This capstone gave us an opportunity to get to that corporate environment type of thing and learn this type of interactions. "

Having the experience of working with engineers from other companies is a valuable and distinguishable skill for graduating engineering students. The international capstone creates an authentic experience of the real world for students.

Aside from the experience of collaborating internationally, this capstone simulated a situation of a small team working within a larger team of engineers to achieve a task. As one student mentioned that international capstone mimicked his work environment during his internship:

"It [The international capstone experience] was like when I was working at Husky. I was working in a small engineering group and there was many other small groups and team leader communicated between teams. The Chinese students, U.S. students and us were a big team of smaller teams too and we had to coordinate with each other. "

Engineering students upon their graduation are required to be able to work in a large team composed of other engineers and none engineers. This international capstone experience provided student with this opportunity by creating an environment where each local team had to function with the rest of teams internationally.

This international capstone not only provides an opportunity for students to learn to function and communicate within their own team, but also to 
experience working in a larger team of engineers. In a regular capstone students are challenged to be able to communicate within their team, which is usually $4-5$ people. In the international team, there is another level of communication that challenges students, and it's between teams. This team was not only required to communicate within their own team of five members but also was required to communicate with another team of four people in China and many other smaller teams in the United States. This capstone gave the students a glimpse of how their work will not only influence their team in their home department but the bigger team as a whole.

Students who had work experiences before chose international capstone because they valued how it resemble the real world experience for them. The challenge of communicating internationally and functioning in a large team was among the skill sets that better prepare student to enter the work force.

This special course prepared students to work productivity with different cultures. Students with this experience can potentially have a better job placement due to the special skill sets they acquired through this project. This international capstone better prepared students for the industry by providing an authentic simulation of work environment.

Their experience simulated a concurrent engineering environment. Since project tasks involved the establishment of two different design team one working on mechanical design and the other working on indusial design. They simultaneously designed throughout the entire design process.

The experience of working in a large team allow students to recognize the value of collaboration rather than competition to achieve high-quality design.

Also, this project emphasized different engineering perspectives within the project team itself, that provided an important experience for students in considering and managing multiple stakeholders.

\subsection{Design philosophy}

Engineers are being trained with different education systems around the world. Being able to understand and appreciate these different perspectives is a phenomenal skill set for students graduating in the 21 st century as they will enter a diverse workforce with people from various educational backgrounds. In this study, it was found that Chinese students were very results driven CEEA16; Paper 120

Dalhousie University; June 19 - 22, 2016 whereas the Canadian students were focusing more on the design process. As one UT student explains:

"One of the biggest challenges in terms of team dynamic was that their expectation was quite different than us. They looked for product rather than process versus over here we are more about how you arrived at this design decision versus over there it's mostly does your product accomplish certain tasks or not and they don't care how you got there. We question ourselves a lot as we go through the process and we think critically and that's how you find out about certain problems too. Because the process is so important it forces you to think which approach to take. Being so result driven will give you a product but not necessary the best one."

This difference between their design philosophies and thinking processes was mentioned various times from students. This difference pushed Chinese students to think more critically and question themselves during the design process. Canadian students were also pushed to their boundaries to present a full-scale physical prototype. It was eye opening for students from both sides on how their educational background and thinking processes affected their design choices and outcomes.

Canadian students acquired specific first-hand knowledge about how industrial designers from the China define and solve technical problems. Their educational diversity led to the development of a global vision for these students. Furthermore, this international learning experience enables students to gain a factual understanding of how engineers and non-engineers from different countries may differ in their technical work.

\subsection{Communication challenges}

During the interviews and from the video recording, it was clear that communication was one of the biggest challenges. The nature of this challenge was both because of the time differences and cultural differences.

The 12-hour time difference made their long distance communication challenging. Because on top of finding a time slot to meet within their team, which was challenge already since in $4^{\text {th }}$ year each of them have their own schedules, they had to schedule a meeting with Chinese students with the 12-hour difference. As one of the Canadian students describes: 
"The 12 hours' time difference was definitely a challenge since we had different schedules too."

They also had to communicate with the US teams separately. Their communication was on a weekly basis so that they could update each other about design decisions. Communicating with Skype made the communications more challenging as it was long distance. As one of the Chinese students mentioned:

"We had to be more patient for things to be done since we had to communicate our ideas across the two teams. "

Working internationally added dimensions to decision making that made their communication more time consuming. Canadian students also recognized the cultural differences with the Chinese students. As one of the Canadian student said:

"the main cultural difference was that Chinese students did not argue or made a counter point, basically they accepted whatever we proposed, I don't know if it was not considered polite or maybe they were not comfortable criticizing us. I'm not sure what the reason was, but they did not ask many questions or did not gave any feedback. Versus when we got any idea or design from them we told them our opinions. I think we learned how to do this during our previous team experiences."

As mentioned above, Canadian students did not receive feedbacks, questions or criticism from Chinese students, but they did give feedback and did ask questions. Interestingly this was appreciated by Chinese students. As one of the Chinese students said during the showcase:

"It was really good to know what other people think about our design; every time we sent our ideas to them they asked us questions that helped us to improve our design."

It was observed that Canadian student asked questions and gave feedback more readily in comparison to Chinese students. This could be potentially because of the cultural differences about how people receive and perceive feedback and criticism. Interestingly Chinese students appreciated the feedback and questions they received regarding their own design.

CEEA16; Paper 120

Dalhousie University; June 19 - 22, 2016

-5 of $7-$
There should be further exploration to see if the reason was actually rooted culturally, or if it was the personality of these specific group of students. As Swearengen et al. argues: "to thrive, future engineers will have to be able to work productively with radically different cultures" [10], we believe that the international capstone enlightened and exposed students to different cultures which is an important competency to have as an engineer.

Aside from the 12-hours difference, the school year timeline was also different which made the communication and team work more challenging. As one Canadian student described:

"The Chinese new year coincided with the time we had the highest workload here. You know prototyping and design review all happens in January and February and it was their holiday."

Different universities have different school year timelines across the world. Students were aware of this challenge from the beginning of the project and they planned ahead of time for it. But this was still challenging to handle.

In this case, Tsinghua University had their school year from September to June versus here in Canada, school year is from September to April. So January and February which was the highest load of the project for $\mathrm{U}$ of $\mathrm{T}$ team coincided the holidays for Chinese team.

Universities that plan to incorporate international capstone, need to make sure they account for this factor as they prepare themselves and the students for this unique experience. This challenge should be addressed while planning and establishing international capstones

\subsection{Multidisciplinary experience}

The difference between the education backgrounds of Chines and Canadian students were also one of the challenges that led to a great learning opportunity for them. University of Toronto students are focused on mechanical design and its analysis while the Chinese students are focused on industrial design. They had to communicate with each other and made sure they understand each other's assumptions and terminologies. As one of the Chinese students mentioned:

"They study engineering and we study design, That was the biggest challenge and difference We had diffident intuitions because of our background and we had to teach each other about it." 
They had different disciplinary knowledge and diversity of perspectives regarding the design that made this a multidisciplinary experience. Students were not only challenged to communicate with people with a different language and cultural background but also different educational backgrounds and expertise. The University of Toronto team was challenged to communicate their idea to industrial designers and Chinese students were challenged to understand the mechanical engineers. This type of interaction and multidisciplinary teamwork is common and required in industry. Literature argues that students must be exposed to a multidisciplinary approach to design which can potentially flourish innovation [11, 12]. Literature also argue that multidisciplinary team's communicate more with each other to transfer their knowledge which leads to greater learning experience[13].

Current literature suggests that working effectively with people who define problems differently helps develop global competency for engineers. In this case, having different intuitions and definitions of design, helped students to develop a global vision [14].

The same experience can be created within universities across Canada. Universities can collaborate with each other and bring their respective expertise to the table. Then student across the country can benefit from the strength of different institutions. These collaborations can even happen nationally and resulting in the same benefits. They are also facilities and resources than can be shared through this experience. In this example, the resource to make the prototype of the car was not available at UT. In China they had the whole facility and recourse which made the design and prototyping possible. International collaboration can provide a platform for resources and facilities to be used internationally. This will allow innovation to flourish as we move beyond barriers from resources.

This international and multidisciplinary experience gave students the opportunity to continue improving their problem-solving, teamwork, and communications skills while learning to apply their newly-acquired technical knowledge to solving technically sophisticated problems.

\subsection{Building Relationships}

Despite the communication challenges, differences between education systems, and the multidisciplinary experiences of team members, the University of Toronto and the Tsinghua University capstone team was able to build a trusting and productive relationship.

At the beginning of the project, the Canadian team traveled to China. This trip was essential for relationship development between the two teams as it allowed for them to get to know each outside of engineering and school work. Through informal, non-academic conversations and outings, the students were able to learn about each other's cultures, personalities and individual aspirations. A Chinese student stated:

"At first I was afraid they we will be very different, but when they came to China I realized that we are all people in our 20s and we have the same hopes and motivation and etc. I realized that we are more similar than not."

Skype meetings and share chat conversations also helped them to builds their long distance relationship throughout the year.

Videos of the Toronto team's project meetings also showed that UT students trusted the TU team because they felt as though they were putting equal effort into the project as they were. UT students felt like they could rely on the TU students because they were always prepared for the team meetings. As one of the Toronto students stated:

"The goal was to build the prototype from the beginning of the project and I think the Chinese universities had the same expectation."

Literature also confirms that building trust and relationship influence communication in global virtual team [15].

\section{CONCLUSION}

This study demonstrates the benefits and importance of giving upper year engineering students the opportunity to participate in international collaborations. International capstone projects give students a special opportunity and equips them with a unique skill set that they have little chance of experiencing through their other course work. By working with students located in another country, with difference educational and cultural backgrounds, Canadian engineering students will gain essential communication skills that they need in their future careers with transnational companies. Furthermore, international collaborations allow for students to become more diverse in their cultural perspectives and gain more real life work experience. 
While these international collaborations are greatly advantages, they are not without their challenges. Students who embark on these projects must be especially committed to developing team relationships and communication because of time and cultural differences. Disparities between educational systems also require students from both countries to reflect upon and adjust their own design processes.

It is our hopes that this paper has offered some insight into some of the possible obstacles but also practices that can make an international capstone successful so that future collaborations can be informed from the get go and operate more effectively.

\section{Acknowledgements}

The authors would like to thank the Natural Sciences and Engineering Research Council of Canada (NSERC) for funding this research through the Chairs in Design Engineering (CDE) grant and Ontario Graduate Scholarship (OGS) for supporting this research.

\section{References}

[1] Marcelo M. Suarez-Orozco, and Carolyn Sattin, "Wanted: global citizens", Journal of Educational Leadership, vol. 64, no. 7, pp. 58-62, 2007.

[2] Stephen M. Brown, and Constance J. Seidner (Eds.), Evaluating corporate training: Models and issues. New York, NY: Springer, 1997.

[3] Holt Zaugg, and Randall S. Davies, "Communication skills to develop trusting relationships on global virtual engineering capstone teams," European Journal of Engineering Education, vol. 38, no. 2, pp. 228-233, 2013.

[4] Caroline Haythornthwaite, "Building social networks via computer networks: creating and sustaining distributed learning communities," In Building Virtual Communities: Learning and Change in Cyberspace, K. A. Renninger and W. Schumar (ed.), 2002.

[5] Stefan Hrastinski, “Asynchronous \& Synchronous ELearning," Educause Quarterly, vol. 31, no. 4, pp. 51-55, 2008 .

[6] Pnina Shachaf, and Noriko Hara, "Behavioral complexity theory of media selection: a proposed theory for global virtual teams," Journal of Information Science, vol. 33, no. 1, pp. 63-75, 2010.

[7] John W. Creswell, Educational Research: Planning, Conducting, and Evaluating Quantitative and Qualitative Research. Upper Saddle River, NJ: Pearson Education, 2012 (4th ed.), 676 pp.

CEEA16; Paper 120

Dalhousie University; June 19 - 22, 2016
[8] Gary Lee Downey, Juan C. Lucena, Barbara M. Moskal, Rosamond Parkhurst, Thomas Bigley, Chris Hays, Brent K. Jesiek, Liam Kelly, Jonson Miller, Sharon Ruff, Jane L. Lehr, and Amy Nicholos-Belo, "The globally competent engineer: Working effectively with people who define problems differently." Journal of Engineering Education, vol. 95, no. 2, pp. 107-122, 2006.

[9] Barney Glaser, and Anselm Strauss, The discovery of grounded theory: strategies for qualitative research. Chicago: Aldine, 1967, 271 pp.

[10] Gary Lee Downey, Juan C. Lucena, Barbara M. Moskal, Rosamond Parkhurst, Thomas Bigley, Chris Hays, Brent K. Jesiek, Liam Kelly, Jonson Miller, Sharon Ruff, Jane L. Lehr, and Amy Nichols-Belo, "The globally competent engineer: working effectively with people who define problems differently," Journal of Engineering Education, vol. 95, no. 2, pp. 107-122, 2006.

[11] E. M. Mielnik, "Concurrent engineering and multidisciplinary engineering education," in Proc. of the 1991 American Society for Engineering Education Annual Conference, New Orleans, LA, June 1991, pp. 1204-1217, 1991

[12] Narges Balouchestani-Asli, Kamran Behdinan, “Are multidisciplinary design capstone's students more innovative than monodisciplinary ones?," in Proc. CEEA Canadian Engineering Education Conf., CEEA2016, (Halifax, Nova Scotia; 19-22 June 2016), 5 pp., 2016.

[13]Narges Balouchestani-Asli, Matthew Kiprop Greenacre, Kamran Behdinan, "Exploring Innovation, Psychological Safety, Communication and Knowledge Application in a Multidisciplinary Capstone Design Course," in Proc. ASEE American Society for Engineering Education Conf., ASEE 123rd Annual, (New Orleans, LA, June 2629 2016), 18 pp., 2016

[14] J. C. Swearengen, Spencer Barnes, Steven Coe, Carsten Reinhardt, and K. Subramanian, "Globalization and the undergraduate manufacturing engineering curriculum," Journal of Engineering Education, vol. 91, no. 2, pp. 255-261, 2002.

[15] Saonee Sarker, Manju Ahuja, Suprateek Sarker, and Sarah Kirkeby, "The role of communication and trust in global virtual teams: a social network perspective," Journal of Management Information Systems, vol. 28, no. 1, pp. 273-309, 2011. 